\title{
PERBEDAAN JUMLAH TROMBOSIT PLATELET RICH PLASMA YANG MENGGUNAKAN TABUNG NATRIUM SITRAT DAN TABUNG ACD-A
}

\author{
Sheila Clarissa ${ }^{1)}$, Jusak Nugraha ${ }^{2)}$, Triagung Ruddy ${ }^{3)}$
}

\begin{abstract}
Background: PRP is a relatively new field and there is still minor researches that are usage. However, PRP can be applied to a lot of various fields. This study willmake a comparison between tubes that have sodium citrate anticoagulant and tubes that have ACD-A anticoagulants, to be able to find out which of the two are able to produce a higher number of PRPs. Objective: To obtain the anticoagulants that produce more platelet countsand to know the difference in the platelet counts in PRPs found in tubes that have sodium citrate anticoagulants and tubes that have ACD-A anticoagulants. Method: This study was an experimental laboratorium research with an equivalent control group design. Data is normally distributed, so that the parametic statistical analysis test uses Paired T-Test. Results: From 32 respondents, there was an increase in both anticoagulant tubes, where the average increase in platelet counts in PRP using sodium citrate tubes was $337593.75 / \mu$ l and the standard deviation was 158795.437 whereas, the average increase in platelet counts in PRP using ACD-A tubes was $909062.50 / \mu L$ and the standard deviation is. 284336.005. The difference in platelet counts in PRP using sodium citrate tubes and ACD-A tubes was stated to be significant because the result of the Paired T-Test analysis showed Sig (2-Tailed) =0,000 ( $p$ <0.05). Conclusion: There was a significant difference platelet counts in PRP using sodium citrate tubes and ACD-A tubes. Tubes that have ACD-A anticoagulants had higher results than the ones that have sodium citrate anticoagulant.
\end{abstract}

Keywords: Platelets, Platelet Rich Plasma, Sodium Citrate, Acid Citrate Dextrose Formula A

\begin{abstract}
ABSTRAK
Latar Belakang: PRP merupakan bidang yang termasuk relatif baru dan masih belum banyak penelitian maupun penggunaannya. PRP dapat diaplikasikan ke berbagai macam bidang.Pada penelitian kali ini, akan dilakukan perbandingan antara tabung yang memiliki antikoagulan natrium sitrat dengan tabung yang memiliki antikoagulan ACD-A sehingga didapatkan suatu antikoagulan yang dapat menghasilkan PRP yang maksimal. Tujuan: Untuk mendapatkan
\end{abstract}


mendapatkan antikoagulan yang menghasilkan jumlah trombosit lebih banyak dan mengetahui perbedaan jumlah trombosit dalam PRP tabung yang memiliki antikoagulan natrium sitrat dan tabung yang memiliki antikoagulan ACD-A. Metode: Penelitian ini merupakan penelitian eksperimental laboratoris dengan equivalent control group design. Data berdistribusi normal, sehingga uji analisis statistik parametrik menggunakan uji Paired TTest. Hasil: Dari 32 responden, didapatkan kenaikan pada kedua tabung antikoagulan, dimana rata-rata kenaikan jumlah trombosit dalam PRP yang menggunakan tabung natrium sitrat adalah 337593.75/ $\mu 1$ dan standar deviasi-nya adalah 158795.437 sedangkan, rata-rata kenaikan jumlah trombosit dalam PRP yang menggunakan tabung ACD-A adalah 909062.50/ $\mu$ Ldan standar deviasi-nya adalah. 284336.005. Perbedaan jumlah trombosit dalam PRP yang menggunakan tabung natrium sitrat dan tabung ACD-A dinyatakan signifikan atau bermakna karena telah diuji dengan menggunakan uji analisis Paired T-Test dan memberikan hasil Sig $(2-$ Tailed $)=0,000(\mathrm{p}<0,05)$ Simpulan: Terdapat perbedaan yang signifikan atau bermakna pada penelitian perbedaan jumlah trombosit dalam PRP yang menggunakan tabung natrium sitrat dan tabung ACD-A. Tabung yang memiliki antikoagulan ACD-A memberikan hasil yang lebih banyak daripada hasil jumlah trombosit dalam PRP dengan tabung yang memiliki antikoagulan natrium sitrat.

Kata Kunci: Trombosit, Platelet Rich Plasma, Natrium Sitrat, Acid Citrate Dextrose Formula-A

\footnotetext{
1) Fakultas Kedokteran Universitas Katolik Widya Mandala Surabaya, Jalan Kalisari Selatan No.1 Surabaya. 2) Departemen Patologi Klinik Fakultas Kedokteran Universitas Katolik Widya Mandala Surabaya. 3) Departemen Obstetri dan Ginekologi Fakultas Kedokteran Universitas Katolik Widya Mandala Surabaya. Alamat korespondensi : shecladefr310@gmail.com
}

\section{PENDAHULUAN}

Pada era modern ini, perkembangan ilmu pengetahuan semakin meningkat di berbagai bidang termasuk bidang kedokteran. Salah satu penelitian yang sedang berkembang adalah Platelet Rich Plasma (PRP) yang pertama kali dipakai oleh Helene Matras pada tahun 1972 untuk membantu penyembuhan luka. ${ }^{1}$
Platelet Rich Plasma (PRP) adalah suatu produk autologous yang diproduksi dari whole blood menggunakan sentrifugasi. Platelet Rich Plasma (PRP) mengandung konsentrasi platelet yang lebih banyak 3 hingga 5 kali lipat di atas nilai dasar. ${ }^{2}$ Platelet sendiri adalah salah satu komponen darah yang memiliki 
struktur seperti cakram, dengan diameter 2 hingga $4 \mu \mathrm{m}^{3}$

Seiring berkembangnya ilmu pengetahuan, saat ini ditemukan bahwa Platelet Rich Plasma sebenarnya kaya akan platelet yang mengandung growth factor (GF). Seluruh growth factor (GF) ini akan bekerja sama untuk meningkatkan proliferasi seluler, meningkatkan formasi matriks, meningkatkan proliferasi osteoblast menjadi osteoid, angiogenesis, merangsang sintesa kolagen (jaringan ikat), mempercepat regenerasi endotel, remodeling epitel dan mempercepat respon homeostasis pada cedera. ${ }^{2}$

\section{Platelet Rich Plasma (PRP)} didapatkan dari darah. Darah yang diambil adalah darah dari pasien itu sendiri (autologous) Perlu dilakukan optimalisasi proses sejak pengambilan darah sampai terbentuknya Platelet Rich Plasma (PRP) yang maksimal. Salah satu proses yang berperan adalah pemberian antikoagulan pada darah tersebut. ${ }^{1}$

Antikoagulan adalah zat yang bekerja untuk menekan, memperlambat, atau mencegah pembekuan darah, atau agen yang bekerja seperti demikian. Cara kerja antikoagulan dengan cara mengikat ion kalsium atau dengan cara menghambat aktivitas thrombin. ${ }^{3}$ Untuk Platelet Rich Plasma (PRP) biasanya menggunakan tabung yang memiliki antikoagulan Acid
Citrate Dextrose Formula A (ACD-A) atau Natrium sitrat. ${ }^{4}$

Pada penelitian kali ini, peneliti ingin melakukan perbandingan antara tabung antikoagulan natrium sitrat dengan tabung antikoagulan Acid Citrat Dextrose Formula A (ACD-A). Peneliti harapkan dari hasil penelitian kali ini akan didapatkan suatu antikoagulan yang dapat menghasilkan Platelet Rich Plasma (PRP) yang lebih banyak.

\section{METODE}

Penelitian ini merupakan penelitian eksperimental laboratoris dengan equivalent control group design dimana antara kelompok kontrol dan kelompok eksperimental mendapat perlakuan dan dibandingkan secara keseluruhan. Besar sampel sebanyak 32 masyarakat umum. Penelitian dilakukan di klinik Jeremy Medical Service. Teknik yang digunakan untuk pengambilan sampel pada penelitian kali ini adalah Non-Probability, Consecutive Sampling yaitu dengan cara memasukkan responden yang memenuhi kriteria eksklusi dan inklusi penelitian sampai jumlah subyek yang diperlukan terpenuhi. Kriteria inklusi, yaitu: bersedia mengikuti penelitian dengan menandatangani informed consent dan berusia 18-40 tahun. Kriteria eksklusi, yaitu: memiliki penyakit dan termasuk kelompok rentan (ibu hamil, anakanak, geriatri, memiliki gangguan jiwa, memiliki disabilitas, penderita HIV dan narapidana). Cara pengumpulan data dengan 
melalui wawancara langsung dan mengambil darah segar responden yang datang ke Klinik Jeremy Medical Service dan sesuai dengan kriteria inklusi dan eksklusi. Lalu darah tersebut disentrifugasi 4000RPM secara differential centrifugation selama 15 menit., setelah terpisahkan lalu diambil PRP-nya dan dihitung jumlah trombosit dengan Hematologi Analyzer. Penelitian ini akan menggunakan variable bebas berskala nominal 2 kelompok (tabung ACD-A dan natrium sitrat) dan variable efek berskala ratio (kadar PRP kontrol dan perlakuan) yang berdistribusi data normal sehingga uji yang akan digunakan adalah uji Paired T-Test yang termasuk distribusi $\mathrm{t}$ (student $t$ test). ${ }^{5}$

\section{HASIL}

\section{Distribusi Sampel Berdasarkan Jenis}

\section{Kelamin}

Tabel 1 Distribusi responden berdasarkan jenis kelamin $(n=32)$

\begin{tabular}{lll}
\hline Jenis Kelamin & $\mathbf{N}$ & $\mathbf{\%}$ \\
\hline Laki-laki & 6 & 18.75 \\
\hline Perempuan & 26 & 81.25 \\
\hline
\end{tabular}

Tabel 2 Distribusi responden berdasarkan kenaikan trombosit pada laki-laki dan perempuan $(\mathrm{n}=32)$

\begin{tabular}{ccccccc}
\hline & \multicolumn{3}{c}{ Natrium sitrat } & \multicolumn{3}{c}{ ACD-A } \\
\cline { 2 - 7 } & Sebel & Sesu & Kenai & Sebe & Sesud & Kena \\
& um & dah & kan & lum & ah & ikan \\
\hline Perem & 247, & 601, & 353, & 233, & 1,161 & 928,1 \\
puan & 231 & 000 & 769 & 346 &, 500 & 54 \\
\hline
\end{tabular}

Laki 219, 486, 267, 218, 1,045 826,3

$\begin{array}{lllllll}- \text { laki } & 333 & 833 & 500 & 667 & , 000 & 33\end{array}$

Berdasarkan hasil penelitian didapatkan jumlah responden dengan jenis kelamin perempuan $(81,25 \%)$ lebih banyak dibandingkan dengan responden jenis kelamin laki-laki $(18,75 \%)$.

Selain itu, dari keseluruhan ratarata pada tabel 2 , dapat disimpulkan bahwa jumlah trombosit dalam PRP pada perempuan lebih banyak dibandingkan dengan laki-laki, baik pada tabung natrium sitrat maupun ACD-A.

\section{Distribusi Sampel Berdasarkan Usia}

Tabel 3 Distribusi responden berdasarkan usia $(n=32)$

\begin{tabular}{lll}
\hline Umur & $\mathbf{n}$ & $\boldsymbol{\%}$ \\
\hline 19 & 1 & 3.13 \\
\hline 21 & 2 & 6.25 \\
\hline 22 & 8 & 25.00 \\
\hline 23 & 4 & 12.50 \\
\hline 24 & 4 & 12.50 \\
\hline 25 & 1 & 3.13 \\
\hline 27 & 5 & 15.63 \\
\hline 29 & 1 & 3.13 \\
\hline 30 & 1 & 3.13 \\
\hline 32 & 1 & 3.13 \\
\hline 35 & 1 & 3.13 \\
\hline 37 & 2 & 6.25 \\
\hline 38 & 1 & 3.13 \\
\hline
\end{tabular}

Tabel 4 Tabel deskriptif berdasarkan usia $(\mathrm{n}=32)$

\begin{tabular}{cccccc}
\hline & Mean & Max & Median & Min & Modus \\
\hline umur & 26 & 38 & 24 & 19 & 22 \\
\hline
\end{tabular}


Tabel 5 Distribusi responden berdasarkan jumlah trombosit pada usia dibawah dan diatas 24 tahun $(\mathrm{n}=32)$

\begin{tabular}{llll}
\hline & & \multicolumn{2}{c}{ Rata-rata berdasarkan umur } \\
\cline { 3 - 4 } & & \multicolumn{1}{c}{$<\mathbf{2 4}$} & \multicolumn{2}{c}{$\mathbf{2 4}$} \\
\hline Natrium & Sebelum & 251579 & 228000 \\
sitrat & Sesudah & 625842 & 512000 \\
\cline { 2 - 4 } & Kenaikan & 374263 & 284000 \\
\hline ACD-A & Sebelum & 234105 & 225462 \\
\cline { 2 - 4 } & Sesudah & 1192421 & 1062538 \\
\cline { 2 - 4 } & Kenaikan & 958316 & 837077
\end{tabular}

Jumlah responden paling banyak adalah responden dengan usia 22 tahun sebanyak 8 orang $(25,00 \%)$. Rata-rata umur responden adalah 26 tahun, nilai tengah umur responden adalah 24 tahun.

Selain itu, dari tabel 5 dapat disimpulkan bahwa jumlah trombosit dalam PRP pada responden berumur lebih muda dari atau sama dengan 24 tahun lebih banyak dibandingkan dengan responden berumur lebih tua dari 24 tahun, baik pada tabung natrium sitrat maupun ACD-A.

\section{Distribusi Responden Berdasarkan} Jumlah Trombosit dalam PRP pada Tabung Natrium Sitrat Sebelum dan

\section{Sesudah Sentrifugasi}

Tabel 6 Distribusi responden berdasarkan jumlah trombosit dalam PRP pada tabung natrium sitrat sebelum dan sesudah sentrifugasi $(\mathrm{n}=32)$

\begin{tabular}{cllll}
\hline Natrium & \multicolumn{2}{l}{ Sebelum } & \multicolumn{2}{l}{ Sesudah } \\
\cline { 2 - 4 } sitrat & $\mathbf{N}$ & $\%$ & $\mathrm{n}$ & $\%$ \\
\hline
\end{tabular}

\begin{tabular}{lllll}
\hline $140.001-$ & 25 & 78.13 & 0 & 0.00 \\
290.000 & & & & \\
\hline $290.001-$ & 7 & 21.88 & 6 & 18.75 \\
440.000 & & & & \\
\hline $440.001-$ & 0 & 0.00 & 14 & 43.75 \\
590.000 & & & & \\
\hline $590.001-$ & 0 & 0.00 & 8 & 25.00 \\
740.000 & & & & \\
\hline $740.001-$ & 0 & 0.00 & 2 & 6.25 \\
890.000 & & & & \\
\hline $890.001-$ & 0 & 0.00 & 2 & 6.25 \\
1.040 .000 & & & & \\
\hline
\end{tabular}

Tabel 7 Tabel deskriptif berdasarkan jumlah trombosit dalam PRP pada tabung natrium sitrat sebelum dan sesudah sentrifugasi $(\mathrm{n}=32)$

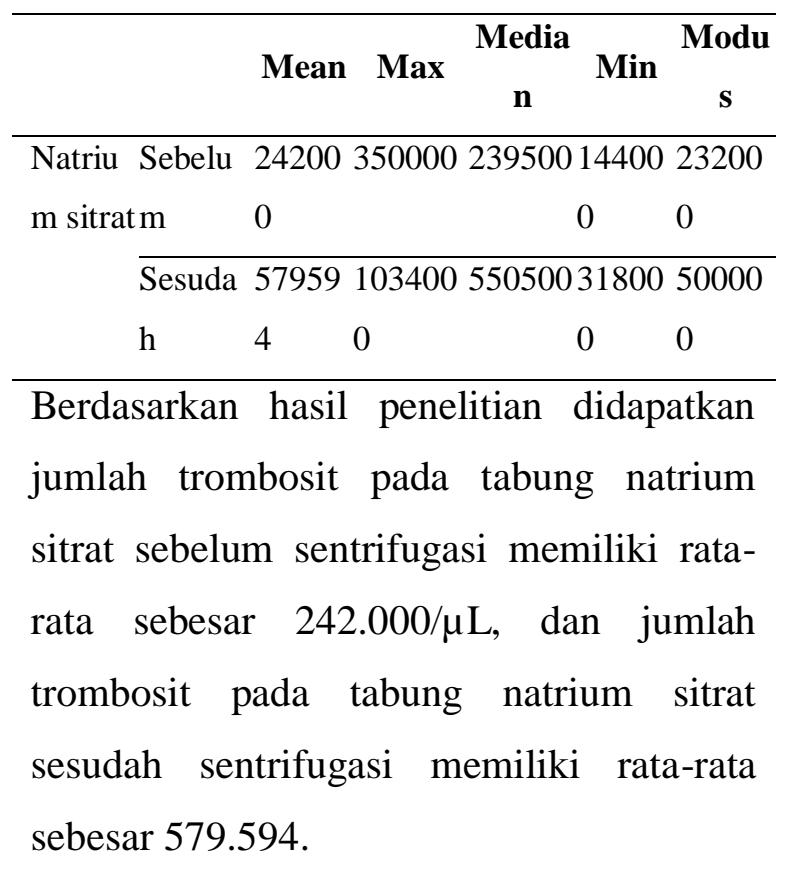

\section{Distribusi Responden Berdasarkan} Jumlah Trombosit dalam PRP pada Tabung ACD-A Sebelum dan Sesudah Sentrifugasi

Tabel 8 Distribusi responden berdasarkan jumlah trombosit dalam PRP pada tabung 
ACD-A sebelum dan sesudah sentrifugasi $(\mathrm{n}=32)$

\begin{tabular}{|c|c|c|c|c|}
\hline \multirow{2}{*}{ ACD-A } & \multicolumn{2}{|c|}{ Sebelum } & \multicolumn{2}{|c|}{ Sesudah } \\
\hline & $\mathbf{n}$ & $\%$ & $\mathrm{n}$ & $\%$ \\
\hline $\begin{array}{l}140.000- \\
410.000\end{array}$ & 32 & 100.00 & 0 & 0.00 \\
\hline $\begin{array}{l}410.001- \\
680.000\end{array}$ & 0 & 0.00 & 1 & 3.13 \\
\hline $\begin{array}{l}680.001- \\
950.000\end{array}$ & 0 & 0.00 & 6 & 18.75 \\
\hline $\begin{array}{l}950-001- \\
1.220 .000\end{array}$ & 0 & 0.00 & 16 & 50.00 \\
\hline $\begin{array}{l}1.220 .001- \\
1.490 .000\end{array}$ & 0 & 0.00 & 5 & 15.63 \\
\hline $\begin{array}{l}1.490 .001- \\
1.760 .000\end{array}$ & 0 & 0.00 & 4 & 12.50 \\
\hline $\begin{array}{l}\text { Tabel } 9 \\
\text { jumlah tro } \\
\text { ACD-A s } \\
(n=32)\end{array}$ & $\begin{array}{l}\text { Tab } \\
\text { mbos } \\
\text { belur }\end{array}$ & $\begin{array}{l}\text { deskri } \\
\text { dalam } \\
\text { lan ses }\end{array}$ & $\begin{array}{l}f \text { be } \\
P \text { pa } \\
\text { ah se }\end{array}$ & $\begin{array}{l}\text { asarkan } \\
\text { tabung } \\
\text { rifugasi }\end{array}$ \\
\hline
\end{tabular}

\begin{tabular}{|c|c|c|c|c|c|}
\hline & Mean & Max & Median & Min & Modus \\
\hline ACSebelum & 230594 & 334000 & 223000 & 14400 & 21600 \\
\hline D- & & & & 0 & 0 \\
\hline \multirow[t]{2}{*}{ A Sesudah } & 113965 & 172800 & 113250 & 62700 & 62700 \\
\hline & 6 & 0 & 0 & 0 & 0 \\
\hline
\end{tabular}

Berdasarkan hasil penelitian didapatkan jumlah trombosit pada tabung ACD-A sebelum sentrifugasi memiliki rata-rata sebesar $230.594 / \mu \mathrm{L}$, dan jumlah trombosit pada tabung ACD-A sesudah sentrifugasi memiliki rata-rata sebesar $1.139 .656 / \mu \mathrm{L}$.

\section{Distribusi Responden Berdasarkan}

Kenaikan Jumlah Trombosit dalam PRP pada Tabung Natrium Sitrat dan ACD-A
Tabel 10 Distribusi responden berdasarkan kenaikan jumlah trombosit dalam PRP pada tabung ACD-A dan tabung natrium sitrat $(n=32)$

\begin{tabular}{|c|c|c|c|c|}
\hline \multirow{2}{*}{ Kenaikan } & \multicolumn{2}{|c|}{ Natrium Sitrat } & \multicolumn{2}{|c|}{ ACD-A } \\
\hline & $\mathbf{n}$ & $\%$ & $\mathbf{n}$ & $\%$ \\
\hline $\begin{array}{l}50.000- \\
300.000\end{array}$ & 14 & 43.75 & 0 & 0.00 \\
\hline $\begin{array}{l}300.001- \\
550.000\end{array}$ & 16 & 50.00 & 4 & 12.50 \\
\hline $\begin{array}{l}550.001- \\
800.000\end{array}$ & 2 & 6.25 & 5 & 15.63 \\
\hline $\begin{array}{l}800-001- \\
1.050 .000\end{array}$ & 0 & 0.00 & 14 & 43.75 \\
\hline $\begin{array}{l}1.050 .001- \\
1.300 .000\end{array}$ & 0 & 0.00 & 5 & 15.63 \\
\hline $\begin{array}{l}1.300 .001- \\
1.550 .000\end{array}$ & 0 & 0.00 & 4 & 12.50 \\
\hline
\end{tabular}

Tabel 11 Tabel deskriptif berdasarkan kenaikan jumlah trombosit dalam PRP pada tabung ACD-A dan tabung natrium sitrat $(n=32)$

Tabung Mean Max Median Min Modus Ke Natrium 33759477800031500057000388000 nai Sitrat

kan ACD-A 9090621511000883500375000375000

Berdasarkan hasil penelitian didapatkan kenaikan jumlah trombosit pada tabung natrium sitrat memiliki rata-rata sebesar 337.594/ $\mu \mathrm{L}$, dan kenaikan jumlah trombosit pada tabung ACD-A memiliki rata-rata sebesar $909.062 / \mu \mathrm{L}$.

Pembahasan Hasil Penelitian Perbedaan Kenaikan Jumlah Trombosit Platelet Rich Plasma yang Menggunakan 
Tabung Natrium Sitrat dan Tabung ACD-A

Tabel 12 Tabel Rata - rata jumlah trombosit Platelet Rich Plasma yang menggunakan tabung natrium sitrat dan tabung ACD-A $(n=32)$

\begin{tabular}{|c|c|c|c|c|c|c|}
\hline & \multicolumn{3}{|c|}{ Natrium Sitrat } & \multicolumn{3}{|c|}{ ACD-A } \\
\hline & $\begin{array}{c}\text { Sebel } \\
\text { um }\end{array}$ & $\begin{array}{l}\text { Sesu } \\
\text { dah }\end{array}$ & $\begin{array}{l}\text { Kena } \\
\text { ikan }\end{array}$ & $\begin{array}{c}\text { Sebel } \\
\text { um }\end{array}$ & $\begin{array}{l}\text { Sesu } \\
\text { dah }\end{array}$ & $\begin{array}{c}\text { Kenai } \\
\text { kan }\end{array}$ \\
\hline Rata & 242, & 579 & 33 & 230,5 & 1,139 & 909 \\
\hline- & 000 & ,59 & 7,5 & 94 & 656 &, 06 \\
\hline Rata & & 4 & 94 & & & 3 \\
\hline
\end{tabular}

Tabel 13 Tabel Hasil Analisis statistik perbedaan kenaikan jumlah trombosit Platelet Rich Plasma yang menggunakan tabung natrium sitrat dan tabung ACD-A $(\mathrm{n}=32)$

\begin{tabular}{lllccl}
\hline & & Mea & & \multicolumn{1}{c}{ Std. } & Std. Error \\
& & n & Deviation & Mean \\
\hline P & Kenaikan & 3375 & 3 & 15879 & 28071.3 \\
a & Natrium & 93.7 & 2 & 5.437 & 33 \\
i & Sitrat & 5 & & & \\
\cline { 2 - 6 } r & Kenaikan & 9090 & 3 & 28433 & 50263.9 \\
& ACD-A & 62.5 & 2 & 6.005 & 79 \\
1 & & 0 & & &
\end{tabular}

Dari hasil rata-rata tersebut diatas didapatkan hasil jumlah trombosit dalam PRP dengan tabung antikoagulan ACD-A

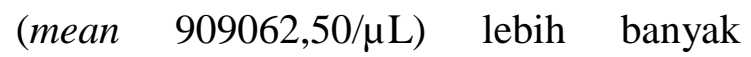
daripada hasil jumlah trombosit dalam PRP dengan tabung antikoagulan natrium

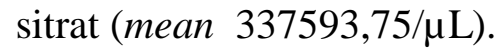

Tabel 14 Tabel Test Distribusi Normal perbedaan kenaikan trombosit Platelet
Rich Plasma yang menggunakan tabung natrium sitrat dan tabung ACD-A ( $\mathrm{n}=32)$

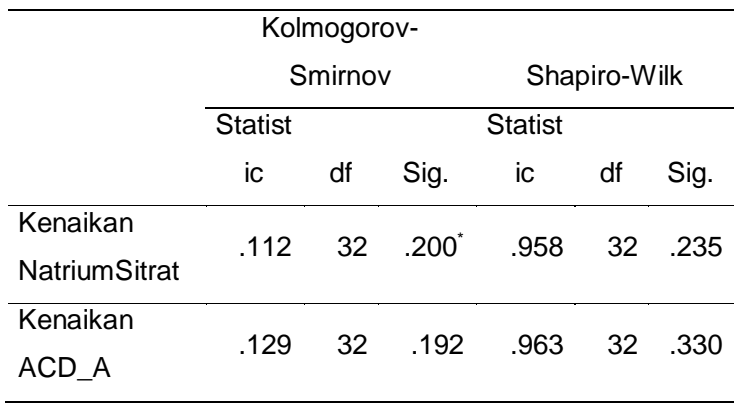

Tabel 15 Tabel Analisis korelasi Paired Ttest perbedaan kenaikan trombosit Platelet Rich Plasma yang menggunakan tabung natrium sitrat dan tabung ACD-A $(n=32)$

\begin{tabular}{|c|c|c|c|c|}
\hline & & $\mathbf{N}$ & $\begin{array}{c}\text { Correlati } \\
\text { on }\end{array}$ & $\begin{array}{c}\text { Sig } \\
\text {. }\end{array}$ \\
\hline Pai & KenaikanNatriumS & 3 & .607 & .00 \\
\hline \multirow[t]{2}{*}{ r 1} & itrat dan & 2 & & 0 \\
\hline & KenaikanACD-A & & & \\
\hline
\end{tabular}

Tabel 16 Tabel Analisis uji Paired T-test perbedaan kenaikan jumlah trombosit Platelet Rich Plasma yang menggunakan tabung natrium sitrat dan tabung ACD-A $(\mathrm{n}=32)$

\begin{tabular}{|c|c|c|c|c|c|c|}
\hline & \multicolumn{3}{|c|}{ Paired Differences } & \multirow[t]{2}{*}{$\mathbf{t}$} & \multirow{2}{*}{$\begin{array}{l}\text { Sig. } \\
(2- \\
\text { tail } \\
\text { ed) }\end{array}$} \\
\hline & & Mean & $\begin{array}{l}\text { Std. } \\
\text { Devi } \\
\text { ation }\end{array}$ & $\begin{array}{l}\text { Std. } \\
\text { Error } \\
\text { Mean }\end{array}$ & & \\
\hline $\mathrm{P}$ & Kenaikan & - & 2263 & 40013.7 & - & .00 \\
\hline $\mathrm{a}$ & Natrium & 5714 & 51.70 & 06935 & 14. & 0 \\
\hline ir & Sitrat - & 68.7 & 8114 & & 28 & \\
\hline 1 & Kenaikan & 5 & & & 18 & \\
\hline & ACD-A & 0000 & & & 25 & \\
\hline
\end{tabular}

Setelah itu, penelitian akan dilanjutkan dengan melakukan uji analisis perbedaan hasil trombosit dalam PRP dalam masing- 
masing tabung tersebut dengan menggunakan Paired T-Test dengan perbedaan dinyatakan signifikan bila $\mathrm{p}<0,05$. Hasil analisis Paired T-Test menunjukan Sig(2-Tailed $)=0,000$, sehingga dapat disimpulkan terdapat perbedaan yang signifikan antara jumlah trombosit dalam Platelet Rich Plasmayang menggunakan tabung natrium sitrat dan tabung ACD-A, dimana jumlah trombosit dalam Platelet Rich Plasma pada Tabung ACD-A lebih banyak.

\section{DISKUSI}

\section{Karakteristik Individu}

\section{Distribusi Responden Berdasarkan}

\section{Jenis Kelamin}

Pada penelitian ini didapatkan rata-rata kenaikan pada tabung natrium sitrat dan rata-rata kenaikan pada tabung ACD-A pada perempuan adalah lebih banyak dibandingkan dengan laki-laki baik pada tabung natrium sitrat maupun ACD-A dimana hal ini sesuai dengan penelitian $\mathrm{J}$. Richard Evanson, M. Kelly Guyton, David L. Oliver, Society of Military Orthopaedic Surgeons, Fort Gordon, yang mengatakan bahwa konsentrasi faktor pertumbuhan dari PRP pada perempuan lebih banyak dibandingkan pada laki-laki. ${ }^{6}$

\section{Distribusi Responden Berdasarkan Usia}

Pada penelitian ini didapatkan jumlah trombosit dalam PRP pada responden yang berumur lebih muda dari atau sama dengan 24 tahun lebih banyak dibandingkan dengan yang berumur lebih tua dari 24 tahun, baik pada tabung natrium sitrat maupun ACD-A dimana hal ini sesuai dengan penelitian J. Richard Evanson, M. Kelly Guyton, David L. Oliver, Society of Military Orthopaedic Surgeons, Fort Gordon, yang mengatakan bahwa konsentrasi faktor pertumbuhan ( EGF, IGF-1, PDGP-AB, PDGF-BB, TGFb-1 ) dari PRP responden yang berumur lebih muda dari atau sama dengan 25 tahun lebih banyak dibandingkan dengan yang berumur lebih tua dari 25 tahun. $^{6}$

Jumlah Trombosit dalam PRP pada Tabung Natrium Sitrat dan Tabung ACD-A

\section{Distribusi Responden Berdasarkan} Jumlah Trombosit dalam PRP pada Tabung Natrium Sitrat Sebelum Sentrifugasi dan Sesudah Sentrifugasi

Berdasarkan hasil penelitian didapatkan jumlah trombosit pada tabung natrium sitrat sebelum sentrifuge ( $242.000 / \mu \mathrm{L})$ mengalami kenaikan jumlah trombosit sesudah sentrifuge ( 579.594).

\section{Distribusi Responden Berdasarkan} Jumlah Trombosit dalam PRP pada Tabung ACD-A Sebelum Sentrifugasi dan Sesudah Sentrifugasi

Pada penilitian didapatkan jumlah trombosit pada tabung ACD-A sebelum 
sentrifuge $(230.594 / \mu \mathrm{L}) \quad$ mengalami peningkatan jumlah sesudah sentrifuge $(1.139 .656 / \mu \mathrm{L})$.

Jadi dapat dilihat adanya kenaikan jumlah trombosit dalam PRP sesudah sentrifugasi dibanding sebelum sentrifugasi baik dengan menggunakan tabung antikoagulan natrium sitrat maupun antikoagulan ACD-A. Hal ini menunjukan jumlah trombosit dalam PRP mengandung jumlah trombosit yang lebih banyak yaitu sebanyak 3 sampai 5 kali lipat di atas nilai dasar. Salah satu proses yang bekerja untuk meningkatkan jumlah trombosit dalam PRP itu adalah sentrifugasi. Menurut Rachita Dhurat dan M.S. Sukesh pada tahun 2014 tentang Principles and Methods of Preparation of Platelet-Rich Plasma: A Review and Author's Perspective di India, proses ini dinamakan differential centrifugation. ${ }^{7}$

Penelitian Dedianto Hidajat, Diah Adriani Malik, S. Buditjahjono, pada tahun 2012 tentang Platelet-Rich Plasma Dalam Dermatologi di Semarang, menyatakan bahwa Platelet Rich Plasma untuk terapi klinis dibutuhkan sekitar 1.000 .000 trombosit per mikroliter. maka Platelet Rich Plasma harus memiliki persentase kenaikan rata-rata sekitar $150 \%$ dalam hitungan platelet, salah satu cara adalah dengan sentrifugasi. ${ }^{8}$
Distribusi Responden Berdasarkan Kenaikan Jumlah Trombosit dalam PRP pada Tabung Natrium Sitrat dan Tabung ACD-A.

Tabung Antikoagulan sangat dibutuhkan dalam proses pembuatannya, Platelet Rich Plasma (PRP). Menurut Rubina Alves, Ramon Grimalt, pada tahun 2018 tentang A Review of Platelet-Rich Plasma: History, Biology, Mechanism of Action, and Classification di Spanyol, antikoagulan yang dipakai dalam prosedur Platelet Rich Plasma (PRP) biasanya adalah Acid Citrate Dextrose Formula A (ACD-A) atau Natrium sitrat. Dari hasil diatas tampak bahwa terjadi kenaikan trombosit dalam PRP baik pada tabung antikoagulan natrium sitrat maupun antikoagulan ACD-A. Tampak pula kenaikan trombosit dalam PRP pada tabung antikoagulan ACD-A (909.062/ $\mu \mathrm{L})$ lebih banyak daripada dengan antikoagulan natrium sitrat $(337.594 / \mu \mathrm{L}) .{ }^{4,9}$

\section{Pembahasan Hasil Analisis Perbedaan} Kenaikan Jumlah Trombosit dalam PRP pada Tabung Natrium Sitrat dan

\section{Tabung ACD-A.}

Dari hasil rata-rata tersebut didapatkan hasil jumlah trombosit dalam PRP dengan tabung antikoagulan ACD-A (mean 909062,50) lebih banyak daripada hasil jumlah trombosit dalam PRP dengan tabung antikoagulan natrium sitrat (mean 
337593,75). Hal ini disebabkan adanya kandungan dekstrosa pada ACD-A sedangkan di dalam natrium sitrat tidak ada. dimana dekstrosa merupakan nutrisi untuk sel darah sehingga dapat meningkatkan kelangsungan hidup dan umur sel darah.

Selanjutnya perbedaan hasil trombosit dalam PRP dalam tabung Antikoagulan ACD-A dibanding tabung antikoagulan natrium sitrat setelah dianalisis dengan menggunakan Paired $T$ Test memberikan hasil Sig(2-Tailed) = $0,000(\mathrm{p}<0,05)$ yang berarti perbedaan ini signifikan atau bemakna, sehingga dapat disimpulkan terdapat perbedaan yang signifikan atau bermakna terhadap jumlah trombosit dalam PRP yang menggunakan antikoagulan natrium sitrat dan antikoagulan ACD-A, dimana tabung yang memiliki antikoagulan ACD-A memberikan hasil yang lebih banyak daripada hasil jumlah trombosit dalam PRP dengan antikoagulan natrium sitrat.

\section{SIMPULAN}

Rata-rata kenaikan jumlah trombosit dalam Platelet Rich Plasma yang menggunakan tabung natrium sitrat adalah $337593.75 / \mu \mathrm{L}$ Rata-rata kenaikan jumlah trombosit dalam Platelet Rich Plasma yang menggunakan tabung ACD-A adalah 909062.50/ $\mu \mathrm{L}$.

Hasil jumlah trombosit dalam PRP dengan tabung antikoagulan Acid Citrate Dextrose
Formula A (ACD-A) (mean 909062,50) lebih banyak daripada dengan tabung antikoagulan natrium sitrat (mean 337593,75). Hal ini menunjukan bahwa salah satu proses yang berperan untuk menghasil jumlah trombosit yang banyak dalam Platelet Rich Plasma adalah pemberian antikoagulan pada darah ${ }^{1}$ Perbedaan jumlah trombosit dalam Platelet Rich Plasma yang menggunakan tabung natrium sitrat dan tabung ACD-A dinyatakan signifikan atau bermakna karena telah diuji dengan menggunakan uji analisis Paired T-Test dan memberikan hasil Sig $(2-$ Tailed $)=0,000(\mathrm{p}<0,05)$.

\section{UCAPAN TERIMA KASIH}

Ucapan terima kasih kepada Benjamin K., dr., MARS selaku dosen pembimbing klinis, Direktur Klinik Rawat Inap Jeremy Medical Service, petugas laboratorium, responden, dan semua pihak yang tidak dapat penulis sebutkan satu-persatu.

\section{DAFTAR PUSTAKA}

1. Langer C, Mahajan V. Platelet-rich plasma in dermatology. JK Science [Internet]. 2014. [cited 2018 Feb 5]; 16: 147-150. Avaible from : https://www.jkscience.org/archives/ volume164/Review Article.pdf

2. Rick G, Craig J, Mark C. PlateletRich Plasma: Properties and Clinical Applications. J Lancaster Gen Hosp[Internet]. 2007. [cited 2018 
Feb 5]; 2: 73-78. Avaible from : http://www.jlgh.org/JLGH/media/Jo urnal-LGH-Media-

Library/Past\%20Issues/Volume\%20 $2 \% 20-$

$\% 20$ Issue \%202/smith_plateletrich_plasma.pdf

3. Dorland WAN. Kamus Saku Kedokteran Dorland Ed. 29. Singapore: Elsevier, 2015.

4. Alves R, Grimalt R. A Review of Platelet-Rich Plasma: History, Biology, Mechanism of Action, and Classification. Ski Appendage Disord [Internet]. 2018. [cited 2018 Mar 20]; 18-24. Avaible from : https://www.karger.com/Article/Pdf/ 477353

5. Sastroasmoro S, Ismael S. Dasardasar Metodologi Penelitian Klinis. Jakarta: Sagung Seto, 2016.

6. Evanson JR, Guyton MK, Oliver DL. Gender and Age Differences in Growth Factor Concentrations From Platelet-Rich Plasma in Adults. Mil Med [Internet]. 2014. [cited 2018 Nov 11]; 179: 799-805. Avable from

https://www.ncbi.nlm.nih.gov/pubm ed/25003868.

7. Dhurat R, Sukesh M. Principles and methods of preparation of plateletrich plasma: A review and author's perspective. J Cutan Aesthet Surg [Internet]. 2014. [cited 2018Mar 16]; 7: 189. Avaible from : https://www.ncbi.nlm.nih.gov/pmc/a rticles/PMC4338460/

8. Hidajat D, Malik DA, Buditjahjono S. Platelet-Rich Plasma Dalam Dermatologi [Internet]. 2012. [cited 2018 Feb 5]; 39: 176-185. Avaible from

http://www.perdoski.or.id/doc/mdvi/ fulltext/25/152/176-185.pdf.

9. Turgeon ML. Clinical Hematology Theory \& Procedures [Internet]. 4th ed. United States of America: Lippincott Williams and Wilkins, 2012 [cited 2018 Mar 28]. Avaible from

https://books.google.co.id/books?id $=\mathrm{cHAjsU} U$ gegpQC $\&$ printsec $=$ frontco ver\&hl=id. 